\title{
$\bullet$ \\ IJCRR \\ Section: Healthcare \\ Role of Polyunsaturated Fatty Acid Derivative Flaxseeds in the Treatment of Dry Eyes- An Overview
}

Sci. Journal Impact

Factor: 6.1 (2018)

ICV: 90.90 (2018)

(c) (i) (3)

Copyright@IJCRR

\author{
Dubey G' ${ }^{1}$ Prabhu Avinash V², Khan T³, Pant K', Ragni K ${ }^{5}$,Chandra Mahesh ${ }^{6}$
}

'Optometry Resident,Department of Optometry, Faculty of Paramedical Sciences, UPUMS, Saifai, Etawah, Uttar Pradesh, India; ${ }^{2}$ Assistant Professor-Grade 2, Faculty of Life and Allied Health Sciences, Ramaiah University, Bangalore, India; ${ }^{3}$ Associate Professor, Departments of Ophthalmology HIMSR; Jamia Hamdard, New Delhi, India; ${ }^{4}$ Associate Professor and Head Faculty of Paramedical Sciences, UPUMS, Saifai, Etawah, Uttar Pradesh, India; ${ }^{5}$ Assistant Professor and Head, Department of Optometry, Era University, Lucknow, Uttar Pradesh, India; ${ }^{6}$ Sr. Optometrist, Department of Ophthalmology, Dr. Sushila Tewari Hospital and Govt. Medical College, Haldwani, Uttarakhand, India.

\section{ABSTRACT}

Introduction: Dry eye is the most common ocular disorder manifested by tear deficiency resulting in discomfort in eyes, visual disturbances, and instability in tear film with a surplus of alternative symptoms like burning of eyes, photophobia, tearing, ocular fatigue, and grittiness that hinder activities of daily living (ADL), therefore compromising the patient's quality of life.

Flaxseed is considered as an emerging food with nutritional characteristics loaded with essential polyunsaturated Omega-3 fatty acids with anti-inflammatory properties. The evidence shows a beneficial effect of nutraceutical supplements containing omega-3 and its derivatives (18; 3n-3; ALA) rich in flaxseeds and relieves symptoms of dry-eye. Therefore, the purpose of this study is to summarize the scientific-based evidence on the role of polyunsaturated fatty acid derivative flaxseed in the treatment of patients suffering from dry eye syndrome.

Methodology: The database collected from PubMed, PubMed Central (PMC), Cochrane library, Google scholar and research gate.

Discussion and Conclusion: At present, there are varieties of buffered formulations containing electrolytes, surfactants, preservatives available in the market that aggravate the patient's symptoms (tear film instability, poor epithelial healing) due to reported cytotoxicity. The nutraceutical, preservative-free supplements are, therefore, better alternatives for managing conjunctival dryness. The limited evidence and researches on flaxseed suggest standardized, well-designed Randomized Control Trials for delivering an accurate dose recommendation for dry eye patients.

Key Words: Dry eye syndrome, Omega-3 fatty acid, Flaxseeds (18: 3n3: ALA), Lacrimal gland, Tear film, Visual discomfort

\section{INTRODUCTION}

Dry eye is a global public-eye health issue characterized by corneal or conjunctival dryness accompanied by eye discomfort, visual disturbance, and tear film instability resulting in an altered pattern of daily living activities (ADL) with a significant effect on the quality of life. ${ }^{1}$ Around $25 \%$ of patients with this syndrome consults eye care professionals. ${ }^{2,3}$ The prevalence of dry eyes reported in North-India is higher, ranging from $18.4 \%$ to $54.3 \%$ with the majority of the patient falling within the age groups of 21-40 years. The overall incidence ranges from $5 \%$ to $35 \%$ due to environmental pollution, climate conditions, life expectancy, lifestyles, and in- creased opioid consumption. ${ }^{4}$ The international workshop on the dry eye (DEWS) classifies into three categories based on its causes, mechanism, and severity of the disease (2007). ${ }^{5}$ The tear film and ocular society (2017) reviewed it's the definition as a multiple factor disease characterized by loss of homeostasis of the tear film with ocular symptoms like increased tear film osmolarity, corneal surface desiccation that leads to instability in tear-film, ocular surface inflammation, and neurosensory anomalies. ${ }^{6}$

This condition is classified as episodic that occurs due to reduced blinking due to environmental or visual tasks saturating the tear stability or chronic disease aggravated by the

\section{Corresponding Author:}

Ms. Ragni Kumari, Assistant Professor and Head, Department of Optometry, Era University, Lucknow, Uttar Pradesh, India. Email: ragnimishraa@gmail.com

ISSN: 2231-2196 (Print)

Received: 16.07 .2020
ISSN: 0975-5241 (Online)

Revised: 19.09 .2020
Accepted: 03.11 .2020
Published: 07.12 .2020 
similar environmental conditions but continue persistently with symptoms and ocular surface damage. ${ }^{7}$ Polyunsaturated fatty acid (PUFA) carries out a vital role during the treatment of dry eyes. An essential PUFA is found in omega-3 and omega- 6 acting as precursors of eicosanoids, regulating the inflammatory process and immune responses. ${ }^{8}$ The Flaxseed is considered to be a nutritionally enriched food loaded with essential polyunsaturated Omega-3 fatty acids with anti-inflammatory properties. ${ }^{9}$ The other potential advantage of flaxseed includes the reduction of cardiovascular diseases, atherosclerosis, diabetes, cancer, arthritis, osteoporosis, autoimmune, and neurological disorders. ${ }^{10}$ The omega- 6 group includes Linoleic acid (LA), gamma-linoleic acid (GLA), dihomogamma-linoleic acid (DGLA), and arachidonic acid (AA). Evidence suggests that the oral intake of omega-3 supplements help in controlling inflammation over the ocular surfaces and relieves the dry eye symptoms. ${ }^{11}$ Therefore, the purpose of this study is to summarize the scientific-based evidence on the role of polyunsaturated fatty acid derivative flaxseed in the treatment of patients suffering from dry eye syndrome.

The information is collected from standard databases such as PubMed, PubMed Central (PMC), Cochrane library, Google scholar, and research gate. The search in PubMed, PubMed central was conducted using the Boolean operators: ("linseed oil"[Mesh Terms] OR ("linseed"[All Fields] AND "oil”[All Fields]) or "linseed oil"[All Fields] or ("flaxseed"[All Fields] and "oil"[All Fields]) or "flaxseed oil"[All Fields]) and ("keratoconjunctivitis sicca"[Mesh Terms] or ("keratoconjunctivitis"[All Fields] and "sicca"[All Fields]) or "keratoconjunctivitis sicca"[All Fields] or ("dry"[All Fields] and "eyes"[All Fields]) or "dry eyes"[All Fields] or "dry eye syndromes"[Mesh Terms] or ("dry"[All Fields] and "eye"[All Fields] and "syndromes"[All Fields]) or "dry eye syndromes"[All Fields] or ("dry"[All Fields] and "eyes"[All Fields])) and ("therapy"[Subheading] or "therapy"[All Fields] or "treatment"[All Fields] OR "therapeutics"[Mesh Terms] or "therapeutics"[All Fields]). In the Cochrane Library, a Medical Subject Headingssearch has performed with the following words flaxseed, dry eye syndrome with a limit of Cochrane reviews, trials, all date publication, and all years with word variations of flaxseed for dry eyes treatment/ syndrome.

\section{Tear Film Mechanism}

The healthy tear film signifies an exclusive fluid layer of approximately $3 \mu \mathrm{m}$ thick and $3 \mu 1$ in a volume covering the outer mucosal surface of the eye. This layer includes a mixture of

a) Lipids-a thin layer (50 to $100 \mathrm{~nm}$ ) secreted from Meibomian glands located at the lid margin that aid in retarding evaporation of tears from the eye surface, b) Aqueous layer secreted from lacrimal gland which also secrets a variety of protein, electrolytes, and water thereby providing oxygen and nutrients to the corneal tissues and further removing the foreign bodies, and

c) Mucin secreted by the specialized goblet cells in the conjunctival epithelium with some transmembrane mucin released into the tear film from the cornea and conjunctival epithelial cells that helps stabilize the tear film and forms the bulk of the tears.

The function of tear-film is to shield the ocular surface from the potentially pathogenic microorganisms. These are classified as 1) basal tears present on the ocular surface, 2) Reflex tears, activated by stimulation, and 3) closed eye tears activates during sleep. The tear turnover rate under standard condition is $1-3 \mu 1 /$ minutes. Its activity is increased due to interaction with any stimulant/irritant particles. The signals received from both parasympathetic and sympathetic nerves via lacrimal, Meibomian, and goblet glands (parasympathetic innervations only) regulate the production of the tear film. These inputs from cornea and lid margins adjust the tear secretions by moving towards the lacrimal puncta and canaliculi from where they drain into the nasolacrimal system. The tear produced help in moistening the ocular surface by blinking mechanism. Full tears absorb through the nasolacrimal duct, and few portions are evaporated. The evaporation increases tear film osmolarity and lead to inflammation of the ocular surface and the lacrimal gland. These conditions lead to dry-eye that seeks an anti-inflammatory therapy to alleviate the symptoms. The high omega- 3 fat content alphalinoleic acid rich in flaxseed soften the secretion so that they can flow, thereby reducing the inflammation. ${ }^{12,13}$

\section{Aetiology/ Risk Factors of Dry Eye}

Several factors are identified repeatedly within the epidemiological studies associated with dry Syndrome. Krenzer et al. reported that chronic androgen deficiency is related to Meibomian gland dysfunction..$^{14}$ Evidence suggests that prolonged wearing of contact lens agitates the symptoms. In comparison, some studies determined that frequent drinking and smoking aggravates the symptoms of dry eyes. ${ }^{15} \mathrm{Em}-$ ploying antihistamine and antidepressants also exacerbate the symptoms. (Table 1) demonstrates some of the aetiological factors that increase its risk in the patients

\section{Sources of Nutritional Supplement}

The omega-3 (n-3) is derived from the family of polyunsaturated fatty acids (PUFA) that are essential but not produced by the body. These fatty acids belong to polyunsaturated fatty acid (n-3). They are the richest in EPA (eicosapentaenoic acid), DHA (docosahexaenoic acid), \& ALA (alphalinolenic acid). ${ }^{7}$ Flaxseed (Linum usitatissimum) is golden yellow or chromatic reddish-brown seed with structure incorporating short-chain PUFA of 18 carbons long alpha Li- 
noleic acid (ALA) that is derived from various soluble and insoluble fibres, Phytoestrogens, along with the group of antioxidants. ${ }^{10}$ Flaxseed constitutes, additionally, the primary source of providing lignan precursors like secoisolariciresinol diglucoside (SDG) to prevent and alleviate lifestylerelated diseases. Its potential advantages are to cut back the symptoms of inflammation ${ }^{9}$ and the potential benefits of diminution of cardiovascular diseases, indurations of the arteries, neurological disorders. ${ }^{10}$ Some report reveals that one tablespoon $(15 \mathrm{ml})$ of flaxseed oil in diet can meet and exceed the daily ALA needs. ${ }^{16}$ India ranks 4th with 0.15 million tons of total flaxseed production. Flaxseed is food consumed by humans while linseed as, used in the trade and for feed purposes. ${ }^{17}$ On the other hand, arachidonic acid (AA) is an omega- 6 metabolite and the precursor of prostaglandins, leukotrienes, and different immune molecules. The omega-3 PUFA metabolites docosahexaenoic acid and eicosapentaenoic acid and fight with arachidonic acid to incorporate in cellular membrane phospholipids. The stability between these two PUFA ends up in an anti-inflammatory or a proinflammatory type in the organism. ${ }^{18}$ The study on animal models reported a higher level of (n-3) PUFA within the tissue layers of the retina and lacrimal system that helps in reducing the inflammation. ${ }^{19}$

\section{Therapeutic Options for Dry Eye}

At present, there are varieties of buffered formulations containing electrolytes, surfactants, preservatives, viscosity agents available in the market for managing instability in the precorneal tear-film and amplifying the tear film breakup time (TFBUT). The majority of it contains a similar composition (chemical properties + preservatives used) (Table 2).

\section{Evidence-Based Studies on Flaxseeds for Dry Eye Syndrome}

Several studies reported cytotoxicity (benzalkonium chloride; BAK) and high prevalence of ocular surface disorders in preserved solutions/ lubricants leading to eye-burning, mild irritation to severe corneal and conjunctival scarring on installation. ${ }^{20-22}$ Andrea Oleñik (2014) reports the beneficial effect of nutraceutical supplements formulations containing omega-3 sources relieves symptoms of dry eye syndrome. ${ }^{23}$ Supplements rich in omega-3 fatty acids are less expensive to buy as compared to artificial tear formulations. ${ }^{24}$

\section{Hormonal Changes}

Several studies emphasize the prevalence of hormonal effect of dry eyes in females, especially in the menopausal or post-menopausal age group. ${ }^{25}$ This possibility might be due to the misbalance between the estrogen and androgen levels that influences the production and mechanism of layers of the tear film. The lower level of these hormones deactivates the activity of the Meibomian gland, alters the ocular surface physiological conditions, and changes the receptor activity leading to dry eye. ${ }^{16}$ Flaxseed being richest in SDG, many studies on human and animal models reported that SDG and its metabolites mediate the lipoproteins and reduce the androgenic complications and oxidative preventions..$^{25}$ The topical application of novel androgenic hormone formulations to the eyelids demonstrates a beneficial effect with diminished side-effects in menopausal women's. ${ }^{24}$ Cetisili (2015) conducted a study on 140 menopausal women and found that the estrogenic action of specific metabolites of flaxseed exhibits a protective effect by decreasing the symptoms and increasing quality of life among menopausal women. A study reports that consuming $90 \mathrm{gms}$ of flaxseed per day creates a positive effect on menopausal symptoms. ${ }^{19}$

\section{Aging}

The older adults are highly susceptible to two sorts of deficiencies because of the deficit lipid layer a) aqueous insufficiency that reduces aqueous secretion from the lacrimal gland and b) evaporation resulting in the unstable tear film. ${ }^{20}$ The prevalence of aqueous insufficiency is $3.90 \%$ among men aged from 50 to 54 years as compared to $7.67 \%$ among men 80 years and older. ${ }^{21}$ Boerner (2000) experiment on 116 patients in an open-label clinical trial with omega-3 supplements and its derivatives Docosahexaenoic acid (DHA) and Alpha-linolenic acid (ALA) rich in flaxseed and found that $98 \%$ of a patient suffering from dry-eye syndrome reported an improvement in their symptoms. ${ }^{22}$

\section{Visual Display Unit}

Working on a visual display unit, laptops, computers for more than 4 hours increases the risk of dry eye syndrome due to reduce blink mechanism that increases the rate of evaporation and causes eye fatigue and headaches affecting eye health and job performance. Buhargava et al. (2015) studied 456 individuals suffering from dry eyes and demonstrated that the group receiving a nutritional supplement of omega-3 fatty acid along with its derivative ALA diminished the symptom, thereby reduced the evaporation rate..$^{23}$

\section{Animal Model}

$\mathrm{Li} \mathrm{Z}$ and colleagues (2014) studied a mouse model to investigate the efficacy of topical application of (n-3) Essential fatty acid (EFA) and hyaluronic acid formulations and found a significant effect of (n-3) EFA on clinical signs and inflammation as compared to hyaluronic formulation tears in dry eye disease. A similar study conducted on a mouse model and found that the topical application of omega-3 fatty acid and its derivative (18: 3n-3: ALA-flaxseed) reduces epithelial damage, the appearance of inflammatory cytokines and macrophage infiltration. The single route administration of flaxseeds either orally or topically was effective in treating 


\section{Combination Therapy}

The nutritional supplement omega-3 fatty acid taken orally or topically might be an option for managing dry eye syndrome. A report suggested that these derivatives when combined with other anti-inflammatory agents, assist in reducing symptoms. A study conducted on a combination of Anti-inflammatory agents (Cyclosporin-A) with alpha Linoleic acid (ALA) and Linoleic acid (LA) formulations that seem to improve the TBUT and considered asA potential treatment for clinical symptoms and physiological changes associated with dry eye syndrome. ${ }^{25}$ When other polyunsaturated fatty acids are combined, they exhibit the effect of omega-3 fatty acids and their derivatives (ALA: flaxseed). Thereby demonstrating substantial evidence of n-3 and its derivatives in the treatment of dry eyes. ${ }^{16}$ The low-dose oral doxycycline combined with flaxseed supplements when given in combination produces a beneficial effect in reducing inflammation. ${ }^{23}$

\section{Comparison between Flaxseed Oil, Oral and Topical Form}

Pinheiro MN (2007) experimented on 38 feminine patients suffering from keratoconjunctivitis sicca. Sjögren's syndrome was arbitrarily allotted into 3 groups $\mathrm{Gp}-1$ receive flaxseed oil (1 g/day dose), Gp-II: flaxseed capsule $2 \mathrm{~g} /$ day dose, while Gp-III in placebo Gp for 180 days and found statistically significant changes $(p<0.05)$ in the symptoms of ocular surface disease index, ocular surface inflammation, Schirmer-I test, and Tear film breakup time (TBUT) when compared to the placebo group. The results found that oral flaxseed oil and capsules 1 or $2 \mathrm{~g}$ /day reduced the ocular surface inflammation and symptoms of keratoconjunctivitis sicca and Sjögren's syndrome. ${ }^{18}$ Flaxseed capsules improve the symptoms as compared to artificial tear formulation. Omega-3 supplement containing flaxseed is cheaper than the tear formulations.

The similar study conducted which 36 patient receiving a daily dose of fish oil, containing Eicosapentaenoic acid (EPA) $450 \mathrm{mg}$ and docosahexaenoic acid (DHA) $300 \mathrm{mg}$, and flaxseed $1000 \mathrm{mg}$ oil for 90 days following baseline and final visits and found that these supplements increase the tear production and tear volume in a patient with the dry eyes syndrome. The application of an artificial tear (n-3) fatty acid-containing carboxymethylcellulose and glycerin, flaxseed and castor oil, and three osmoprotectants (levocarnitine, erythritol, and trehalose) when compared with an artificial tear (Refresh Optive Advanced [ROA]) over 242 subjects showed significant improvement $(\mathrm{P}<0.05) .{ }^{19}$ These findings suggest that the flaxseed play a beneficial role if administered either orally, topically or in oil form to treat the dry eye syndrome.

\section{CONCLUSION}

There are varieties of artificial tear buffered formulations of electrolyte, surfactant, preservatives in the market, that aggravate the symptoms of the patient due to reported cytotoxicity. Therefore, nutraceutical, preservative-free supplements are safer ways to treat conjunctival dryness. The omega-3 fatty acid and its derivatives: alpha-linolenic acid (ALA) rich in flaxseeds, eicosapentaenoic acid (EPA), and docosahexaenoic acid (DHA] with a chemical formula [18: 3(n-3); ALA, EPA, DHA] are essential acids helps to increase the tear substitute in the dry eyes. Flaxseed not only improves the quality of Meibomian gland secretion but also stimulates aqueous tear secretion via its anti-inflammatory properties on the dysfunctional lacrimal gland. Referring to many databases; we can suggest that flaxseed can play a beneficial role in treating dry-eye syndrome if applied either locally, topically, or in an oil-based form. The limited evidence and researches on flaxseed suggest a standardized, well-designed randomized controlled trials for delivering an accurate dose recommendation for dry eye patients.

\section{ACKNOWLEDGEMENTS}

The authors would like thanks Department of Optometry, Faculty of Paramedical Sciences, Saifai, Etawah for providing all possible support for smooth conduction of this article. I would also like to extend my regards to my colleagues for their guidance and timely help throughout the study. Authors acknowledge the immense help received from the scholars whose articles are cited and included in references to this manuscript. The authors are also grateful to authors/editors/publishers of all those articles, journals and books from where the literature for this article has been reviewed and discussed.

Funding: No funding sources.

Conflict of interest: Authors agree that there is no source of conflict of interest

\section{REFERENCES}

1. Liu NN, Liu L, Li J, Sun Y. Prevalence of and risk factors for dry eye symptom in mainland china: a systematic review and metaanalysis. J Ophth 2014; Article ID 748654.

2. Miljanović B, Dana R, Sullivan DA, Schaumberg DA. Impact of dry eye syndrome on vision-related quality of life. Am J Ophth 2007;143(3):409-415.

3. O'Brien PD, Collum LM. Dry eye: diagnosis and current treatment strategies. Curr Aller Asth Rep 2004; 4(4): 314-319.

4. Titiyal JS, Falera RC, Kaur M, Sharma V, Sharma N. Prevalence and risk factors of dry eye disease in North India: Ocular surface disease index-based cross-sectional hospital study. Indian J Ophth 2018; 66(2): 207-211. 
5. The definition and classification of dry eye disease: report of the Definition and Classification Subcommittee of the International Dry Eye WorkShop. Ocular Surface 2007; 5(2): 75-92.

6. Doughty MJ. Rose bengal staining as an assessment of ocular surface damage and recovery in dry eye disease-a review. Contact lens \& anterior eye: J Br Cont Lens Ass 2013; 36(6): 272280.

7. Foulks GN. Pharmacological management of dry eye in the elderly patient. Drug Aging. 2008; 25(2): 105-118.

8. Oleñik A. Effectiveness and tolerability of dietary supplementation with a combination of omega-3 polyunsaturated fatty acids and antioxidants in the treatment of dry eye symptoms: results of a prospective study. Clin Ophth (Auckland, N.Z.) 2014; 8:169176.

9. Dupasquier CM, Dibrov E, Kneesh AL, Cheung PK, Lee KG, Alexander HK., Yeganeh, BK, Moghadasian MH, \& Pierce GN. Dietary flaxseed inhibits atherosclerosis in the LDL receptordeficient mouse in part through antiproliferative and anti-inflammatory actions. Am J Phys Heart Circ Phys 2007; 293(4): H2394-H2402.

10. Goyal A, Sharma V, Upadhyay N, Gill S, Sihag M. Flax and flaxseed oil: an ancient medicine \& modern functional food. J Food Sci Techn 2014; 51(9): 1633-1653.

11. Jackson MA, Burrell K, Gaddie IB, Richardson SD. Efficacy of a new prescription-only medical food supplement in alleviating signs and symptoms of dry eye, with or without concomitant cyclosporine A. Clin. Ophth 2011; 5: 1201-1206.

12. Dartt DA, Willcox MD. Complexity of the tear film: importance in homeostasis and dysfunction during disease. Expt. Eye Res. 2013; 117: 1-3. https://doi.org/10.1016/j.exer.2013.10.008

13. Charlene Laino. Flaxseed Oil Supplements May Help Dry Eyes. Web med archives [Internet] [Last accessed on May 28 2020] https://www.webmd.com/eye-health/news/20111028/flaxseedoil-supplements-may-help-dry-eyes\#1.

14. Krenzer KL, Dana MR, Ullman MD, Cermak JM, Tolls DB, Evans JE, et al. Effect of androgen deficiency on the human meibomian gland and ocular surface. J. Clinical Endoc. Met. 2000; 85(12): 4874-4882.

15. Lee AJ, Lee J, Saw SM, Gazzard G, Koh D, Widjaja D, et al. Prevalence and risk factors associated with dry eye symptoms: a population-based study in Indonesia. Br J Ophth 2002; 86(12): 1347-1351.

16. Kris-Etherton PM, Taylor DS, Yu-Poth S, Huth P, Moriarty K, Fishell V, et al. Polyunsaturated fatty acids in the food chain in the United States. Amer. J. Clin. Nutrition 2000; 71(1): 179S$88 \mathrm{~S}$.

17. Diane H. Morris. Linseed in the ruminant diet adding linseed to feed enhances the fat profile of milk Winnipeg, MB, Flax Council of Canada. [Internet]. [Last accessed 06/2020]. https:// flaxcouncil.ca/wp-content/uploads/2015/02/Milk_R2 final.pdf.

18. Simon E, Bardet B, Grégoire S, Acar N, Bron AM, CreuzotGarcher CP, Bretillon L. Decreasing dietary linoleic acid promotes long-chain omega-3 fatty acid incorporation into rat retina and modifies gene expression. Expt Eye Res 2011; 93(5), 628-635.

19. Simon E, Bardet B, Grégoire S, Acar N, Bron AM, CreuzotGarcher CP, Bretillon L. Decreasing dietary linoleic acid promotes long-chain omega-3 fatty acid incorporation into rat retina and modifies gene expression. Expt Eye Res 2011; 93(5): 628-635.

20. Tong L, Petznick A, Lee S, Tan J. Choice of artificial tear formulation for patients with dry eye: where do we start? Cornea 2012; 31(1): 32-36.

21. Baudouin C, Labbé A, Liang H, Pauly A, Brignole-Baudouin F. Preservatives in eyedrops: the good, the bad and the ugly. Prog Ret Eye Res 2010; 29(4): 312-334.

22. Jaenen N, Baudouin C, Pouliquen P, Manni G, Figueiredo A, Zeyen T. Ocular symptoms and signs with preserved and preservative-free glaucoma medications. Eur. J. Ophth. 2007; 17(3): 341-349.

23. Lodha VS. Modified Schirmer Test Screening forDry Eye Disease in Rural Population. Int J Cur Res Rev 2015; 7 (18): 38-40.

24. Ngo W, Srinivasan S, Houtman D, Jones L. The relief of dry eye signs and symptoms using a combination of lubricants, lid hygiene and ocular nutraceuticals. J Ophth 2017; 10(1): 26-33.

25. Schaumberg DA, Sullivan DA, Buring JE, Dana MR. Prevalence of dry eye syndrome among US women. Am J Ophth 2003;136(2):318-326.

Table 1: Risk Factor and Symptomsof Dry Eye Syndrome.

\begin{tabular}{|c|c|c|}
\hline Risk Factor & Etiological factors & Symptoms \\
\hline Ageing & Age and feminine sex affected most. ${ }^{20}$ & $\begin{array}{l}\text { Lid laxity, sebaceous gland atrophy, metaplasia, } \\
\text { decrease in tear volume with exaggerated tear } \\
\text { break-up time and dry eye. } .^{21}\end{array}$ \\
\hline Hormonal changes & $\begin{array}{l}\text { 1) Menopausal and post-menopausal women } \\
\text { 2) Women taking oral contraceptive pills }\end{array}$ & $\begin{array}{l}\text { 1) Significant decrease in tear production within } \\
\text { the } 6^{\text {th }} \text { decade of life } e^{24} \\
\text { 2) Higher goblet cell density }{ }^{25}\end{array}$ \\
\hline Environment & $\begin{array}{l}\text { 1) Relative humidity }(\mathrm{RH}) \\
\text { 2) Indoor environment. }{ }^{14} \\
\text { 3) Exposure to sun, dust, pollution, and wind } \\
\text { and extreme temperatures. }\end{array}$ & $\begin{array}{l}\text { Low RH }(30 \%) \text { and high temperature influences } \\
\text { the thermal climate and influence the precorneal } \\
\text { tear film leading to corneal or conjunctival dry- } \\
\text { ness. }{ }^{15}\end{array}$ \\
\hline Computer visuals & $\begin{array}{l}\text { Computers, watching television, and prolonged } \\
\text { reading. }{ }^{2}\end{array}$ & $\begin{array}{l}\text { Prolong working reduces the blink eye mechanism } \\
\text { that causes the tears to evaporate and results in the } \\
\text { dry eye } \mathrm{e}^{13}\end{array}$ \\
\hline Vitamin-A deficiency & Corneal dryness (Xerosis) ${ }^{19}$ & $\begin{array}{l}\text { Due to deficit diet in children and adults due to the } \\
\text { consumption of alcohol, routine smoking habits. }\end{array}$ \\
\hline
\end{tabular}


Table 2: Evidence-based artificial tear formulation and combination therapies for Dry eye $\mathrm{e}^{12,13}$

\section{Artificial Tear Formulation}

Optive Allergan

RestasisAllergan

Soothe

Original Systane

Systane

SystaneUltra
Optive Allergan provides the osmoprotection of the ocular surface against the high osmolarity of tear-film.

It enhances the activity of tear production (cyclosporine)

It helps in increasing the thickness of lipid layer post 1 min of instillation into the eye and produces effect after 1 month of application

It enhances the effect of cyclosporine A

Systane helps in maintaining the stability of the precorneal tear film, thus increases the tear break-up time (TBUT).

The $\mathrm{pH}$ of Systane ultra is 7.9 that helps strengthen the dynamic cross-linking of HP-Gaur and borate and permits the tear film to imitate like healthy eyes.

\section{Combination therapies}

Restasis +original Systane were statistically better than Restasis + Refresh Tears (Allergan). ${ }^{21}$

Pieces of evidence suggested that Original Systanealone gives a positive result than Restasis + Refresh Tears (Allergan). ${ }^{21}$ 